\title{
SISTEM PENDUKUNG KEPUTUSAN UNTUK MENENTUKAN TINGKAT MINAT \\ MASYARAKAT DALAM MEMILIH \\ TANAMAN HIAS MENGGUNAKAN METODE SAW
}

\author{
Anita $^{1}$, Khairunisa Fitri \\ Email : anitayakub_pilchan@yahoo.com ${ }^{1}$ \\ DOI: http://dx.doi.org/10.31869/rtj.v4i1.2454
}

\begin{abstract}
Ornamental plants are plants that have aesthetic and aesthetic value, often used to decorate yards, gardens or rooms in homes, office buildings, hotels, restaurants. Like fashion, trends in ornamental plants come and go and people have tastes that tend to change. Ornamental plants such as Aglonema, Anthurium, Calathea, Monstera Adansoni, Sansevieria are currently the prima donna and in demand by the public. To assist in determining and knowing which ornamental plants are most in demand by the public, it is necessary to build a decision support system using the SAW method. The SAW method is a weighted addition method that has the ability to solve problems from several criteria, so that it will produce alternative ornamental plants based on their level of interest (the most desirable) more quickly and precisely. There are several criteria used in the decision support system to determine the level of public interest in choosing ornamental plants using the SAW method, namely the shape / type of leaf, leaf color, price and care.
\end{abstract}

Keywords: Decision Support System, Ornamental Plants, SAW Method

Abstrak: Tanaman hias adalah tanaman yang mempunyai nilai keindahan dan estetika, sering digunakan sebagai penghias pekarangan, taman atau ruangan di rumah-rumah, gedung perkantoran, hotel, restaurant. Ibarat mode, tren tanaman hias muncul silih berganti dan masyarakat memiliki selera yang cenderung berubah. Tanaman hias seperti Aglonema, Anthurium, Calathea, Monstera Adansoni, Sansevieria, saat ini menjadi primadona dan diminati oleh masyarakat. Untuk membantu dalam menentukan dan mengetahui tanaman hias yang paling diminati oleh masyarakat maka diperlukan membangun sistem pendukung keputusan menggunakan metode SAW. Metode SAW merupakan metode penjumlahan terbobot yang memilki kemampuan untuk menyelesaikan masalah dari beberapa kriteria, sehingga akan menghasilkan alternatif tanaman hias berdasarkan tingkat minatnya (yang paling diminati) secara lebih cepat dan tepat. Adapun beberapa kriteria yang digunakan dalam sistem pendukung kepetusan untuk menentukan tingkat minat masyarakat dalam memilih tanaman hias menggunakan metode SAW yaitu bentuk/jenis daun, warna daun, harga dan perawatan.

Kata Kunci : Sistem Pendukung Keputusan, Tanaman Hias, Metode SAW

\section{PENDAHULUAN}

Estetika tumbuhan kini sedang diminati sebagian masyarakat, sehingga tidak mengherankan jika belakangan ini banyak orang yang ingin memiliki tanaman hias. Tanaman hias sebagai sebuah komoditas, sesuai fungsinya adalah sebagai elemen atau unsur penghias. Kehadiran tanaman hias telah menjadi sebuah kebutuhan bagi sebagian masyarakat, antara lain sebagai hobi, penghias maupun koleksi.

Tanaman hias adalah tanaman yang mempunyai nilai keindahan dan estetika baik karena bentuk tanaman, warna dan bentuk daun, tajuk maupun bentuk pohon/batang, warna dan keharuman bunganya, sering digunakan sebagai penghias pekarangan, taman atau ruangan di rumah-rumah, gedung perkantoran, hotel, restaurant [1]. Ibarat mode, tren tanaman hias muncul silih berganti dan masyarakat memiliki selera yang cenderung berubah. Apabila ada tanaman yang lebih lebih indah dan menarik yang sesuai dengan tren yang berlaku, maka selera masyarakat terhadap suatu tanaman hias akan berubah.

Tanaman hias seperti Aglonema, Anthurium, Calathea, Monstera Adansoni, Sansevieria, saat ini menjadi primadona dan diminati oleh masyarakat. Tentunya masyarakat memiliki minat yang berbeda beda dalam memilih tanaman hias. Pada umumnya masyarakat dalam memilih tanaman 
hias akan melihat karakteristik yang ada pada tanaman hias seperti bentuk/jenis daun, warna daun, harga dan perawatannya.

Oleh karena itu dalam penelitian ini akan dikembangkan sistem pendukung keputusan untuk menentukan tingkat minat masyarakat dalam memilih tanaman hias dengan menggunakan metode SAW. Metode SAW dikenal sebagai penjumlahan terbobot. Metode ini menentukan nilai bobot untuk setiap atribut, yang dilanjutkan dengan proses perangkingan. Sehingga akan menghasilkan alternatif tanaman hias yang paling diminati dari lima alternatif tanaman hias dengan perhitungan yang cukup tepat.

\section{METODE PENELITIAN}

\section{Sistem Pendukung Keputusan}

Konsep Sistem Pendukung Keputusan (SPK) pertama kali diungkap pada tahun 1970an oleh Michael S.Scott Morton dengan istilah Management Decision System. Sistem Pendukung Keputusan (Decision Support Systems atau DSS) merupakan suatu informasi interaktif yang menyediakan informasi, pemodelan, dan pemanipulasian data [2]. DSS biasanya dibangun untuk mendukung solusi atas suatu masalah-masalah untuk mengevaluasi suatu peluang.

\section{Metode SAW (Simple Additive Weighting)}

Metode SAW (Simple Additive Weighting) sering juga dikenal istilah metode penjumlahan terbobot. Konsep dasar metode SAW adalah mencari penjumlahan terbobot dari rating kinerja pada setiap alternatif pada semua atribut. Metode SAW membutuhkan proses normalisasi matriks keputusan (X) ke suatu skala yang dapat diperbandingkan dengan semua rating alternatif yang ada [3].

Langkah Penyelesaian SAW sebagai berikut :

1. Menentukan kriteria-kriteria yang akan dijadikan acuan dalam pengambilan keputusan, yaitu $C i$.

2. Menentukan rating kecocokan setiap alternatif pada setiap kriteria.

3. Membuat matriks keputusan berdasarkan kriteria $(\mathrm{Ci})$, kemudian melakukan normalisasi matriks berdasarkan persamaan yang disesuaikan dengan jenis atribut (atribut keuntungan ataupun atribut biaya) sehingga diperoleh matriks ternormalisasi $R$.

4. Hasil akhir diperoleh dari proses perankingan yaitu penjumlahan dari perkalian matriks ternormalisasi $R$ dengan vektor bobot sehingga diperoleh nilai terbesar yang dipilih sebagai alternatif terbaik $(A i)$ sebagai solusi [4].

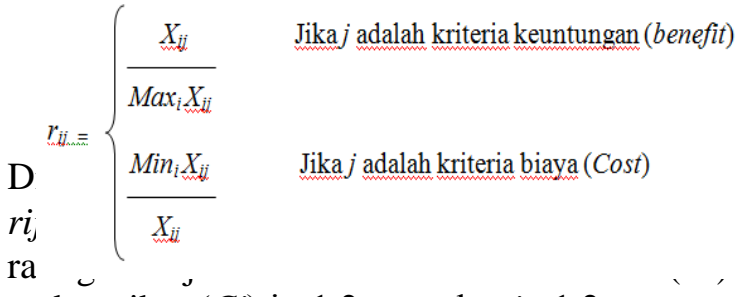
pada atribut $(C j) \mathrm{i}=1,2 \ldots, \mathrm{m}$ dan $j=1,2 \ldots, \mathrm{n}$.

Max = Nilai maksimum dari setiap baris dan kolom.

Min = Nilai minimum dari setiap baris dan kolom.

$X i j=$ Baris dan kolom dari matriks.

$V_{i}=\sum_{j=1}^{n} W_{j} r_{i j}$

$w i=$ bobot yang telah ditentukan.

$r i j=$ normalisasi matriks.

Nilai $V i$ yang lebih besar mengidentifikasikan bahwa alternative $A i$ lebih terpilih.

\section{HASIL DAN PEMBAHASAN \\ Analisa Masalah}

Sistem Pendukung Keputusan Untuk Menentukan Tingkat Minat Masyarakat Dalam Memilih Tanaman Hias berdasarkan kriteriakriteria yang telah ditentukan. Data sample yang telah diambil diolah dengan menggunakan metode SAW (Simple Additive Weighting) untuk menghasilkan perangkingan tanaman hias berdasarkan tingkat minatnya (yang paling diminati)

\section{Analisa Proses}

Sebelum merancang sistem dan melakukan implementasi sistem, maka perlu ditentukan terlebih dahulu kriteria yang dibutuhkan dalam pengambilan keputusan menentukan tingkat minat masyarakat dalam memilih tanaman hias menggunakan metode SAW (Simple Additive Weighting) sebagai berikut: 
Tabel 1. Kriteria

\begin{tabular}{|l|l|l|}
\hline Kriteria & $\begin{array}{l}\text { Nama } \\
\text { Kriteria }\end{array}$ & $\begin{array}{l}\text { Bobot } \\
\text { Kriteria }\end{array}$ \\
\hline C1 & $\begin{array}{l}\text { Bentuk } \\
\text { Daun/Jenis } \\
\text { Daun }\end{array}$ & 0,4 \\
\hline C2 & Warna Daun & 0,3 \\
\hline C3 & Harga & 0,2 \\
\hline C4 & Perawatan & 0,1 \\
\hline
\end{tabular}

Tabel 2. Tabel Kriteria Bentuk Daun $\left(\mathrm{C}_{1}\right)$

\begin{tabular}{|l|l|l|}
\hline No & $\begin{array}{l}\text { Bentuk } \\
\text { Daun/Jenis } \\
\text { Daun }\end{array}$ & $\begin{array}{l}\text { Nilai/ } \\
\text { Bobot }\end{array}$ \\
\hline 1 & $\begin{array}{l}\text { Berdaun Panjang } \\
\text { Tebal }\end{array}$ & 1 \\
\hline 2 & Berdaun Lebar & 2 \\
\hline 3 & $\begin{array}{l}\text { Berdaun Lonjong } \\
\text { Lerdaun Oval } \\
4\end{array}$ & $\begin{array}{l}\text { Berdaun Unik / } \\
\text { Bolong }\end{array}$ \\
\hline 5 & 5 \\
\hline
\end{tabular}

Tabel 3. Tabel Kriteria Warna Daun $\left(\mathrm{C}_{2}\right)$

\begin{tabular}{|l|l|l|}
\hline No & Warna Daun & $\begin{array}{l}\text { Nilai/ } \\
\text { Bobot }\end{array}$ \\
\hline 1 & Satu Warna & 1 \\
\hline 2 & Dua Warna & 3 \\
\hline 3 & $\begin{array}{l}\text { Banyak } \\
\text { Varian Warna }\end{array}$ & 5 \\
\hline
\end{tabular}

Tabel 4. Tabel Kriteria Harga $\left(\mathrm{C}_{3}\right)$

\begin{tabular}{|l|l|l|}
\hline No & Harga & Nilai/Bobot \\
\hline 1 & Rp.30.000 - & 2 \\
& Rp. 150.000 & \\
Ribu & Rp. 160.000 - & 3 \\
\hline 2 & Rp. 250.000 & \\
& Ribu & \\
\hline
\end{tabular}

\begin{tabular}{|l|lr|l|}
\hline 3 & $\begin{array}{l}\text { Rp. } 260.000- \\
\text { Rp. } 350.000\end{array}$ & 4 \\
Ribu & & \\
\hline 4 & $\begin{array}{l}\text { Rp. } 360.000- \\
\text { Rp. } 500.000\end{array}$ & 5 \\
Ribu & & \\
\hline
\end{tabular}

Tabel 5. Tabel Kriteria Perawatan $\left(\mathrm{C}_{4}\right)$

\begin{tabular}{|l|l|l|}
\hline No & Perawatan & Nilai/Bobot \\
\hline 1 & Sulit & 2 \\
\hline 2 & Cukup Sulit & 3 \\
\hline 3 & Mudah & 4 \\
\hline 4 & Sangat Mudah & 5 \\
\hline
\end{tabular}

Adapun data observasi dari tanaman hias adalah dapat dilihat pada tabel 6 dibawah ini :

Tabel 6. Data Observasi Tanaman Hias

\begin{tabular}{|c|c|c|c|c|c|}
\hline \multirow{2}{*}{$\begin{array}{l}\mathbf{N} \\
\mathbf{o}\end{array}$} & \multirow{2}{*}{$\begin{array}{l}\text { Tanama } \\
\text { n } \\
\text { Hias }\end{array}$} & \multicolumn{4}{|c|}{ Kriteria } \\
\hline & & $\mathbf{C}_{1}$ & $\mathrm{C}_{2}$ & $\mathbf{C}_{3}$ & $\mathrm{C}_{4}$ \\
\hline 1 & $\begin{array}{l}\text { Aglonem } \\
a\left(\mathrm{~A}_{1}\right)\end{array}$ & $\begin{array}{l}\text { Berdau } \\
\text { n Oval } \\
\text { Lancip }\end{array}$ & $\begin{array}{l}\text { Ban } \\
\text { yak } \\
\text { Vari } \\
\text { an } \\
\text { War } \\
\text { na }\end{array}$ & $\begin{array}{l}\text { Rp. } \\
260 . \\
000 \\
- \\
\text { Rp. } \\
350 . \\
000 \\
\text { Ribu }\end{array}$ & $\begin{array}{l}\text { Cuk } \\
\text { up } \\
\text { Suli } \\
\text { t }\end{array}$ \\
\hline 2 & $\begin{array}{l}\text { Anthoriu } \\
m\left(\mathrm{~A}_{2}\right)\end{array}$ & $\begin{array}{l}\text { Berdau } \\
\text { n Lebar }\end{array}$ & $\begin{array}{l}\text { Satu } \\
\text { War } \\
\text { na }\end{array}$ & $\begin{array}{l}\text { Rp. } \\
160 . \\
000 \\
- \\
\text { Rp. } \\
250 . \\
000 \\
\text { Ribu }\end{array}$ & $\begin{array}{l}\mathrm{Mu} \\
\text { dah }\end{array}$ \\
\hline 3 & $\begin{array}{l}\text { calathea } \\
\left(\mathrm{A}_{3}\right)\end{array}$ & $\begin{array}{l}\text { Berdau } \\
\mathrm{n} \\
\text { Lonjon } \\
\mathrm{g}\end{array}$ & $\begin{array}{l}\text { Ban } \\
\text { yak } \\
\text { Vari } \\
\text { an } \\
\text { War } \\
\text { na }\end{array}$ & $\begin{array}{l}\text { Rp. } \\
30.0 \\
00- \\
\text { Rp. } \\
150 . \\
000 \\
\text { Ribu }\end{array}$ & $\begin{array}{l}\mathrm{Mu} \\
\text { dah }\end{array}$ \\
\hline 4 & $\begin{array}{l}\text { Monstera } \\
\text { Adansoni } \\
\left(\mathrm{A}_{4}\right)\end{array}$ & $\begin{array}{l}\text { Berdau } \\
\mathrm{n} \\
\text { Unik/B } \\
\text { olong }\end{array}$ & $\begin{array}{l}\text { Dua } \\
\text { War } \\
\text { na }\end{array}$ & $\begin{array}{l}\text { Rp. } \\
360 . \\
000 \\
-\end{array}$ & $\begin{array}{l}\mathrm{Mu} \\
\text { dah }\end{array}$ \\
\hline
\end{tabular}




\begin{tabular}{|c|c|c|c|c|c|}
\hline & & & & $\begin{array}{l}\text { Rp. } \\
500 . \\
000 \\
\text { Ribu }\end{array}$ & \\
\hline 5 & $\begin{array}{l}\text { Sanse } \\
\text { vieria } \\
\left(\mathrm{A}_{5}\right)\end{array}$ & $\begin{array}{l}\text { Berdau } \\
\mathrm{n} \\
\text { Panjang } \\
\text { Tebal }\end{array}$ & $\begin{array}{l}\text { Ban } \\
\text { yak } \\
\text { Vari } \\
\text { an } \\
\text { War } \\
\text { na }\end{array}$ & $\begin{array}{l}\text { Rp. } \\
30.0 \\
00- \\
\text { Rp. } \\
150 . \\
000 \\
\text { Ribu }\end{array}$ & $\begin{array}{l}\text { San } \\
\text { gat } \\
\text { Mu } \\
\text { dah }\end{array}$ \\
\hline
\end{tabular}

Adapun rating kecocokan dari setiap alternatif dapat dilihat pada tabel 7 dibawah dibawah ini:

Tabel 7. Rating Kecocokan Dari Setiap Alternatif

\begin{tabular}{|l|l|l|l|l|l|}
\hline No & $\begin{array}{l}\text { Tanaman } \\
\text { Hias }\end{array}$ & \multicolumn{4}{|l|}{ Kriteria } \\
\cline { 2 - 6 } & $\mathbf{C}_{\mathbf{1}}$ & $\mathbf{C}_{\mathbf{2}}$ & $\mathbf{C}_{\mathbf{3}}$ & $\mathbf{C}_{\mathbf{4}}$ \\
\hline 1 & $\begin{array}{l}\text { Aglonema } \\
\left(\mathrm{A}_{1}\right)\end{array}$ & 4 & 5 & 4 & 3 \\
\hline 3 & $\begin{array}{l}\text { Anthorium } \\
\left(\mathrm{A}_{2}\right)\end{array}$ & 2 & 1 & 3 & 4 \\
\hline 4 & calathea $\left(\mathrm{A}_{3}\right)$ & 3 & 5 & 2 & 4 \\
\hline 5 & $\begin{array}{l}\text { Monstera } \\
\text { Adansoni } \\
\left(\mathrm{A}_{4}\right)\end{array}$ & 5 & 3 & 5 & 4 \\
\hline & $\begin{array}{l}\text { Sanseniera } \\
\left(\mathrm{A}_{5}\right)\end{array}$ & 1 & 3 & 2 & 5 \\
\hline
\end{tabular}

Normalisasi Matriks Input (X) ke matriks $\mathrm{R}$ dalam menormalisasi matriks $\mathrm{X}$ ke dalam matriks $\mathrm{R}$, maka yang harus dilakukan adalah menentukan Nilai $\mathrm{R}$ dari masing-masing Kriteria, dengan rumus sebagai berikut:

a. Untuk Bentuk / Jenis Daun $\left(\mathrm{C}_{1}\right)$

$$
\begin{aligned}
\mathrm{R}_{1.1} & =\frac{4}{\operatorname{ax}\{(4),(2),(3),(5),(1)\}} \\
& =\frac{4}{5}=0,8 \\
\mathrm{R}_{1.2} & =\frac{2}{\operatorname{Max}\{(4),(2),(3),(5),(1)\}} \\
& =\frac{2}{5}=0,4 \\
\mathrm{R}_{1.3} & =\frac{5}{\operatorname{Max}\{(4),(2),(3),(5),(1)\}} \\
& =\frac{3}{5}=0,6 \\
\mathrm{R}_{1.4} & =\frac{5}{\operatorname{Max}\{(4),(2),(3),(5),(1)\}} \\
& =\frac{5}{5}=1
\end{aligned}
$$

$$
\begin{aligned}
\mathrm{R}_{1.5} & =\frac{1}{\operatorname{Max}\{(4),(2),(3),(5),(1)\}} \\
& =\frac{1}{5}=0,2
\end{aligned}
$$

b. Warna Daun $\left(\mathrm{C}_{2}\right)$

$$
\begin{aligned}
\mathrm{R}_{2.1} & =\frac{5}{\operatorname{lax}\{(5),(1),(5),(3),(3)\}} \\
& =\frac{5}{5}=1 \\
\mathrm{R}_{2.2} & =\frac{1}{\operatorname{lax}\{(5),(1),(5),(3),(3)\}} \\
& =\frac{1}{5}=0,2 \\
\mathrm{R}_{2.3} & =\frac{5}{\operatorname{ax}\{(5),(1),(5),(3),(3)\}} \\
& =\frac{5}{5}=1 \\
\mathrm{R}_{2.4} & =\frac{3}{\operatorname{Max}\{(5),(1),(5),(3),(3)\}} \\
& =\frac{3}{5}=0,6 \\
\mathrm{R}_{2.5} & =\frac{3}{\operatorname{Max}\{(5),(1),(5),(3),(3)\}} \\
& =\frac{3}{5}=0,6
\end{aligned}
$$

c. Harga $\left(\mathrm{C}_{3}\right)$

$$
\begin{aligned}
\mathrm{R}_{3.1} & =\frac{4}{\operatorname{Max}\{(4),(3),(2),(5),(2)\}} \\
& =\frac{4}{5}=0,8
\end{aligned}
$$$$
\mathrm{R}_{3.2}=\frac{3}{\operatorname{Max}\{(4),(3),(2),(5),(2)\}}
$$$$
=\stackrel{5}{5}=0,6
$$$$
\mathrm{R}_{3.3}=\frac{2}{\operatorname{Max}\{(4),(3),(2),(5),(2)\}}
$$$$
={ }^{2} \overline{5}=0,4
$$$$
\mathrm{R}_{3.4}=\frac{5}{\operatorname{Max}\{(4),(3),(2),(5),(2)\}}
$$$$
={ }^{3} \overline{5}=1
$$$$
\mathrm{R}_{3.5}=\frac{2}{\operatorname{Max}\{(4),(3),(2),(5),(2)\}}
$$$$
={ }^{<} \overline{5}=0,4
$$

d. Perawatan $\left(\mathrm{C}_{4}\right)$

$$
\begin{aligned}
\mathrm{R}_{4.1} & =\frac{3}{\operatorname{ax~}\{(3),(4),(4),(4),(5)\}} \\
& ={ }^{3}-=0,6 \\
\mathrm{R}_{4.2} & =\frac{4}{\operatorname{Tax}\{(3),(4),(4),(4),(5)\}}
\end{aligned}
$$




$$
\begin{aligned}
& =\frac{4}{5}=0,8 \\
\mathrm{R}_{4.3} & =\frac{4}{\operatorname{lax}\{(3),(4),(4),(4),(5)\}} \\
& =\frac{7}{5}=0,8 \\
\mathrm{R}_{4.4} & =\frac{4}{\operatorname{lax}\{(3),(4),(4),(4),(5)\}} \\
& =\frac{4}{5}=0,8 \\
\mathrm{R}_{4.5} & =\frac{5}{\operatorname{Iax}\{(3),(4),(4),(4),(5)\}} \\
& =\frac{j}{5}=1
\end{aligned}
$$

Maka matriks "R" adalah sebagai Berikut :

Table 8. Matriks Normalisasi

\begin{tabular}{|l|l|l|l|l|l|}
\hline No & Tanaman & \multicolumn{4}{|l|}{ Kriteria } \\
\cline { 2 - 6 } & Hias & $\mathbf{C}_{\mathbf{1}}$ & $\mathbf{C}_{\mathbf{2}}$ & $\mathbf{C}_{\mathbf{3}}$ & $\mathbf{C}_{\mathbf{4}}$ \\
\hline 1 & $\begin{array}{l}\text { Aglonema } \\
\left(\mathrm{A}_{1}\right)\end{array}$ & 0,8 & 1 & 0,8 & 0,6 \\
\hline 2 & $\begin{array}{l}\text { Anthorium } \\
\left(\mathrm{A}_{2}\right)\end{array}$ & 0,4 & 0,2 & 0,6 & 0,8 \\
\hline 3 & $\begin{array}{l}\text { calathea } \\
\left(\mathrm{A}_{3}\right)\end{array}$ & 0,6 & 1 & 0,4 & 0,8 \\
\hline 4 & $\begin{array}{l}\text { Monstera } \\
\text { Adansoni } \\
\left(\mathrm{A}_{4}\right)\end{array}$ & 1 & 0,6 & 1 & 0,8 \\
\hline 5 & $\begin{array}{l}\text { Sanseniera } \\
\left(\mathrm{A}_{5}\right)\end{array}$ & 0,2 & 0,6 & 0,4 & 1 \\
\hline
\end{tabular}

e. Menentukan Rating

Untuk mencari nilai dari tanaman hias, untuk menentukan minat masyarakat dalam memilih tanamanh hias, maka nilai $\mathrm{V}_{1}$ harus diketahui terlebih dahulu dengan menggunakan rumus perhitungan.

Menentukan nilai dari $\mathrm{V}_{1}$ sampai dengan $\mathrm{V}_{5}$ maka dapat dilihat seperti dibawah ini ;

$\mathrm{V}_{1}=(0,4 * 0,8)+(0,3 * 1)+(0,2 * 0,8)+$ $(0,1 * 0,6)$

$$
\begin{aligned}
& =0,32+0,3+0,16+0,06 \\
& =0,84
\end{aligned}
$$

$\mathrm{V}_{2}=(0,4 * 0,4)+(0,3 * 0,2)+(0,2 * 0,6)+$ $(0,1 * 0,8)$

$$
=0,16+0,06+0,12+0,08
$$

$$
\begin{aligned}
& =0,42 \\
\mathrm{~V}_{3} & =(0,4 * 0,6)+(0,3 * 1)+(0,2 * 0,4)+ \\
(0,1 & * 0,8) \\
& =0,24+0,30+0,08+0,08 \\
& =0,70 \\
\mathrm{~V}_{4} & =(0,4 * 1)+(0,3 * 0,6)+(0,2 * 1)+(0,1 \\
* 0,8) & \\
& =0,4+0,18+0,2+0,08 \\
& =0,86 \\
\mathrm{~V}_{5} & =(0,4 * 0,2)+(0,3 * 0,6)+(0,2 * 0,4)+ \\
(0,1 & * 1) \\
& =0,08+0,18+0,08+0,1 \\
& =0,44
\end{aligned}
$$

Dari hasil perhitungan $\mathrm{V}_{1}$ sampai dengan dengan $V_{5}$, maka dapat dibuat tabel penentuan rangking, seperti tabel berikut:

Table 10. Penentuan Rangking

\begin{tabular}{|l|l|l|l|}
\hline $\begin{array}{l}\text { N } \\
\text { o }\end{array}$ & $\begin{array}{l}\text { Alternatif / } \\
\text { Tanaman Hias }\end{array}$ & Nilai & $\begin{array}{l}\text { Rangk } \\
\text { ing }\end{array}$ \\
\hline 1. & $\begin{array}{l}\text { Monstera } \\
\text { Adansoni }\left(\mathrm{A}_{4}\right)\end{array}$ & 0,86 & 1 \\
\hline 2. & Aglonema $\left(\mathrm{A}_{1}\right)$ & 0,84 & 2 \\
\hline 3. & Calathea $\left(\mathrm{A}_{3}\right)$ & 0,70 & 3 \\
\hline 4. & $\begin{array}{l}\text { Sansevieria } \\
\left(\mathrm{A}_{5}\right)\end{array}$ & 0,44 & 4 \\
\hline 5. & Anthorium $\left(\mathrm{A}_{2}\right)$ & 0,42 & 5 \\
\hline
\end{tabular}

Nilai yang terbesar ada pada $\mathrm{V}_{4}$ yaitu pada alternatif $\left(\mathrm{A}_{4}\right)$ tanaman hias Monstera Adansoni, sehingga dapat disimpulkan bahwa $\mathrm{V}_{4} /$ alternatif $\left(\mathrm{A}_{4}\right)$ tanaman hias Monstera Adansoni adalah tanaman hias yang paling diminati oeh masyarakat.

\section{Implementasi Sistem}

Implementasi sistem merupakan tahap penerapan setelah proses analisa dan perancangan sistem, dimana data akan diproses kedalam perangkat lunak sistem. Kemudian dilakukan pengujian, apakah sistem dapat berjalan sesuai dengan kebutuhan. Pengujian yang dilakukan adalah pengujian metode dengan mengggunakan metode SAW (Simple Additive Weigthing). 
Metode Simple Additive Weigthing sebuah kerangka untuk mengambil keputusan dengan efektif [5]. Untuk Untuk masuk ke dalam sistem, maka harus melakukan login terlebih dahulu dengan memasukkan data user name dan password pada halaman login seperti terlihat pada gambar berikut :

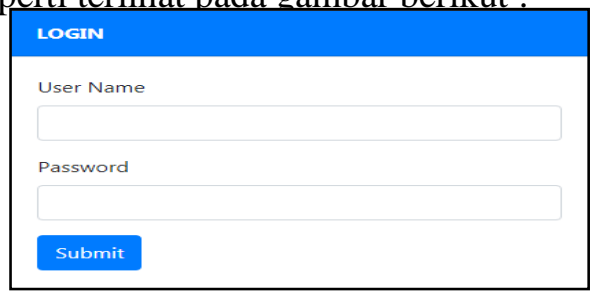

Gambar 1. Halaman Login

Halaman Utama (Home) : Pada Halaman uatama (home) menampilkan tampilan awal sistem berupa judul yaitu Sistem Pendukung Keputusan Untuk Menentukan Tingkat Minat Masyarakat Dalam Memilih Tanaman Hias dan dapat memilih menu-menu yang ada.

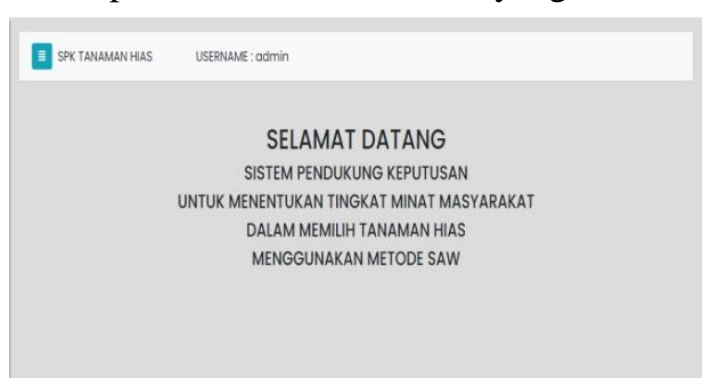

Gambar 2. Halaman Utama (Home)

Halaman Data Tanaman : Pada halaman atau menu data tanaman menampilkan data tanaman yaitu nama tanaman dan keterangan. Admin dapat menambah, merubah dan menghapus data tanaman hias yang akan dijadikan sample atau alternatif dalam penelitian.

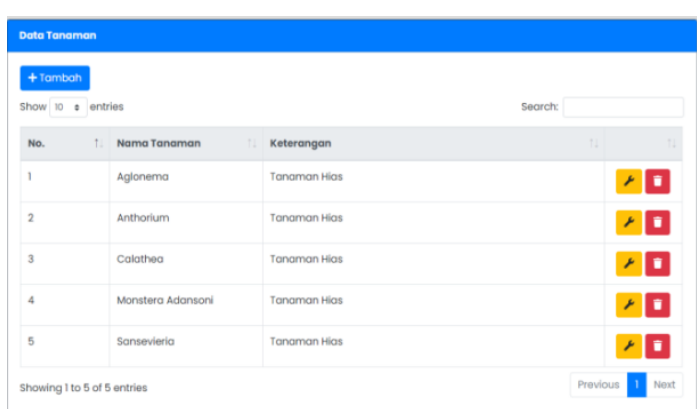

Gambar 3. Halaman Data Tanaman

Halaman Data Kriteria : Halaman atau menu data kriteria digunakan untuk menampilkan data kriteria apa saja yang dipakai utnuk melakukan penilaian dalam memilih tanaman hias dan menampilkan kriteria bobot nilai data tanaman hias atau data sampel yang digunakan untuk melakukan perhitungan dengan metode Simple Additive Weighting. Pada halaman data kriteria ini dapat melakukan tambah tanaman, merubah dan menghapus nilai data tanaman.

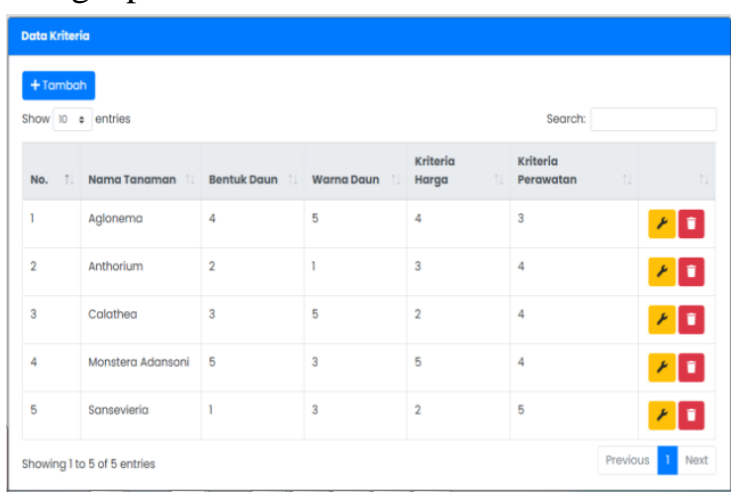

Gambar 4. Halaman Data Kriteria

Halaman Perangkingan : Pada halaman atau menu perangkingan ini untuk dapat melihat hasil perangkingan harus menekan tombol proses, maka sistem akan menampilkan nilai akhir dan hasil perangkingan dari setiap alternatif tanaman hias. Nilai akhir dan hasil perangkingan diperoleh dengan menggunakan perhitungan metode SAW. Dimana nilai akhir hasil yang lebih besar mengindikasikan bahwa alternatif atau tanaman hias tersebut lebih terpilih (diminati). Nilai akhir dan hasil perangkingan yang ditampilkan secara berurutan dari yang paling besar sampai paling rendah.

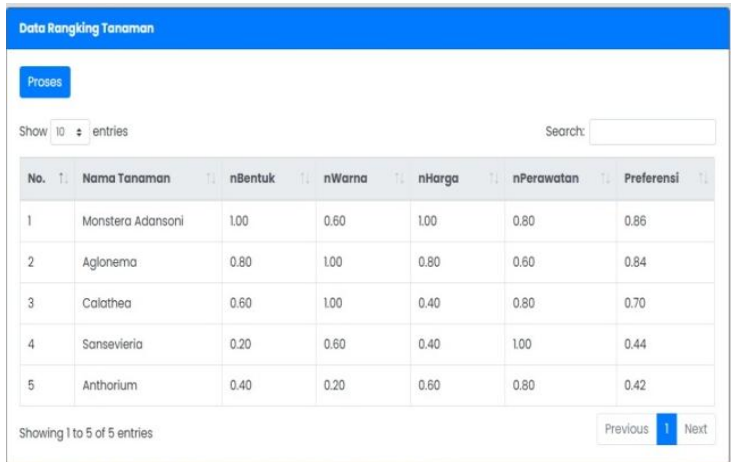

Gambar 5. Halaman Perangkingan

Halaman Grafik Perangkingan : Halaman atau menu grafik perangkingan menampilkan hasil perangkingan berbentuk grafik diagram batang, berdasarkan tingkatan nilai akhir dan hasil perangkingan dari setiap alternatif tanaman hias. 


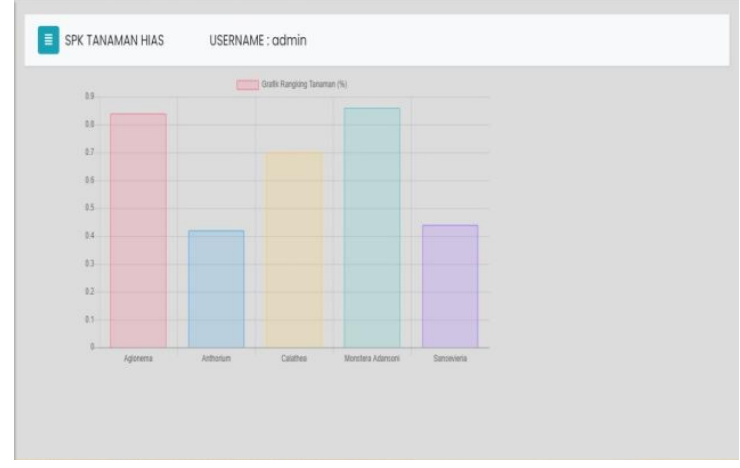

Gambar 6. Halaman Perangkingan

\section{SIMPULAN DAN SARAN \\ Simpulan}

Kesimpulan yang dapat diambil pada penelitian Sistem Pendukung Keputusan Untuk Menentukan Tingkat Minat Masyarakat Dalam Memilih Tanaman Hias Menggunakan Metode SAW (Simple Additive Weighting) adalah :

1. Sistem Pendukung Keputusan Untuk Menentukan Tingkat Minat Masyarakat Dalam Memilih Tanaman Hias menggunakan metode Simple Additive Weighting (SAW) berdasarkan kriteria-kriteria yang telah ditentukan, dapat menghasilkan perangkingan tanaman hias berdasarkan yang paling diminati oleh masyarakat..

2. Metode SAW (Simple Additive Weighting) dapat memberikan alternatif keputusan yang terbaik dalam pengambilan keputusan dalam pemilihan tanaman hias bagi masyarakat..

3. Sistem ini dapat menjadi alat bantu (tools) bagi pengambilan keputusan untuk pihak penjual tanaman hias.

\section{Saran}

Berdasarkan hasil penelitian yang dilakukan oleh penulis maka diususlkan beberapa saran untuk penelitian lebih lanjut antara lain :

1. Dari hasil penelitian yang telah dilakukan, maka diharapkan untuk pengembangan penelitian selanjutnya dapat menggunakan metode lain seperti AHP, Topsis, dan lain-lain.

2. Pada penelitian yang telah dilakukan perancangan dan implementasi sistem pendukung keputusan yaitu berbasis web, maka untuk penelitian selanjutnya dapat dilakukan secara java visual, android, dan lain-lain.

3. Jenis tanaman hias yang menjadi subjek penelitian dapat diperluas dengan menggunakan jenis tanaman hias lainnya.

\section{DAFTAR PUSTAKA}

[1] Dirgantari Putri. 2019. Faktor - Faktor Yang Mempengaruhi Permintaan Tanaman Hias Di Desa Bangun Sari Kecamatan Tanjung Morawa Kabupaten Deli Serdang. Access From (repository.uma.ac.id)

[2] Kusrini. 2007. Konsep dan Aplikasi Sistem Pendukung Keputusan. Yogyakarta : Andi Offset.

[3] Eniyati, S. 2011. Perancangan Sistem Pendukung Pengambilan Keputusan untuk Penerimaan Beasiswa dengan Metode SAW (Simpke Additive Weighting). Jurnal Teknologi Informasi DINAMIK Volume 16,no.2 , 16, 171-176.

[4] Wau, Klaudius Andrisan. 2015. Sistem Pendukung Keputusan Pelelangan Barang Dengan Metode Simple Additive Weighting (Saw) (Studi Kasus : Pt. Pegadaian Cabang Pasar Merah Medan.

[5] Sutabri, T., 2014, Analisa Sistem Informasi Andi Offset, Yogyakarta. 